\title{
An NMR and enzyme study of the carbon metabolism of Neisseria meningitidis
}

\author{
Matthew P. Leighton, ${ }^{1}+$ David J. Kelly, ${ }^{2}$ Michael P. Williamson ${ }^{2}$ \\ and Jonathan G. Shaw ${ }^{1}$
}

Author for correspondence: Jonathan G. Shaw. Tel: +44 114271 3517. Fax: +44 1142739926. e-mail: J.G.Shaw@sheffield.ac.uk

\footnotetext{
1 Division of Molecular and Genetic Medicine, University of Sheffield Medical School, Sheffield S10 2RX, UK

2 Department of Molecular Biology and Biotechnology, Firth Court University of Sheffield, Sheffield S10 2TN, UK
}

The pathogenic neisseriae are fastidious bacteria that are only able to grow on a restricted range of carbon sources. The genome sequence of Neisseria meningitidis strain MC58 predicts the presence of a complete citric acid cycle (CAC), but there have been no detailed biochemical studies of carbon metabolism in this important pathogen. In this study, both NMR and conventional enzyme assays were used to investigate the central metabolic pathways of a serogroup B strain (K454). ${ }^{13} \mathrm{C}-\mathrm{NMR}$ labelling patterns of amino acids from hydrolysed cell proteins after growth with either 2- or 3$\left[{ }^{13} \mathrm{C}\right]$ pyruvate were consistent with the operation of a complete oxidative CAC. Enzyme assays showed that cell-free extracts contained all the CAC enzymes predicted from the genome sequence, including a membrane-bound malate:quinone oxidoreductase which is present in place of the conventional NAD-linked cytoplasmic malate dehydrogenase. ${ }^{1} \mathrm{H}-\mathrm{NMR}$ studies showed that growth on glucose, lactate and, especially, pyruvate, resulted in the excretion of significant amounts of acetate into the culture supernatant. This occurred via the phosphotransacetylase (PTA)-acetate kinase (ACK) pathway. Extremely high specific activities of PTA (7-14 $\mathrm{mol} \mathrm{min}^{-1} \mathrm{mg}^{-1}$ ) were detected in cell-free extracts, although ACK activities were much lower (46-298 $\left.\mathrm{nmol} \mathrm{min}{ }^{-1} \mathrm{mg}^{-1}\right)$. Expression of PTA and ACK activities was not co-ordinately regulated during growth on combinations of carbon sources. This may be related to the presence of two ackA paralogues in $N$. meningitidis which are, unusually, unlinked to the pta gene.

Keywords: nuclear magnetic resonance, phosphotransacetylase-acetate kinase pathway, proton NMR, carbon-13 NMR

\section{INTRODUCTION}

Neisseria meningitidis is an obligate human pathogen that causes meningitis and sepsis syndrome. The disease arises in a number of otherwise healthy individuals after colonization of the nasopharynx (Klein et al., 1993). The vast majority of meningococcal-human interactions are commensal, but occasionally host, bacterial, or environmental changes initiate a shift from a commensal

\footnotetext{
†Present address: Wellcome Trust Centre for Cell-Matrix Research, Schoo of Biological Sciences, University of Manchester, Stopford Building, Oxford Road, Manchester M13 9PT, UK.

Abbreviations: ACK, acetate kinase; AP5A, $P^{1}, P^{5}$-di(adenosine-5') pentaphosphate; CAC, citric acid cycle; CFE, cell-free extract; $L D H$, lactate dehydrogenase; PEP, phosphoenolpyruvate; PTA, phosphotransacetylase; TSP, trimethylsilyl propionate.
}

to a pathogenic relationship. From this state, the bacteria invade via the nasopharyngeal epithelium and disseminate into the bloodstream to cause potentially fatal meningitis or septicaemia. Although meningitis is the more commonly presented outcome, septicaemia is the more devastating form of the disease (Klein et al., 1993). However, the factors that are responsible for the meningococcal shift from commensal to pathogen are still unknown.

Many recent investigations of $N$. meningitidis have concentrated on a number of potential virulence factors. Very little is known about the possible links between metabolic processes and pathogenic mechanisms which may lead to the onset of systemic infection. Growth of N. meningitidis requires pyruvate, lactate, or glucose as a sole carbon source, in addition to carbon dioxide (Chapin, 1918). N. meningitidis is biochemically similar 
to Neisseria gonorrhoeae, but very little work has been carried out into neisserial physiology over the past 20 years (Holten, 1974a, b; Jyssum, 1960).

The study of the catabolism of glucose by $N$. meningitidis and $N$. gonorrhoeae has indicated the involvement of the Entner-Doudoroff pathway, the pentose phosphate pathway and the citric acid cycle (CAC) (Morse et al., 1979). Investigations concerning the catabolism of pyruvate by N. meningitidis and N. gonorrhoeae indicated involvement of the CAC (Holten, 1975, 1976a). A pyruvate dehydrogenase system is present in $\mathrm{N}$. meningitidis, which converts pyruvate to acetyl-CoA and $\mathrm{CO}_{2}$ (Jyssum, 1960). The acetyl-CoA is then more slowly catabolized via the CAC. Lactate is utilized via its conversion to pyruvate by at least three different meningococcal lactate dehydrogenase (LDH) enzymes (Erwin \& Gotschlich, 1993, 1996). Studies of growth on lactate and glucose have been carried out with $N$. gonorrhoeae, which showed an accumulation of acetate in the medium; this is utilized to a limited extent when the primary carbon source has been depleted (Hebeler \& Morse, 1976; Morse et al., 1979; Morse, 1979).

The study of the CAC of Neisseria began with the work of Tonhazy \& Pelczar (1953). They investigated the rate of oxidation and total oxygen consumption of intermediates of the CAC in N. gonorrhoeae. This method of analysis only led to a tentative prediction of the likely order of utilization of the substrates. Jyssum (1960) initiated studies on the CAC in N. meningitidis. The individual reactions of a number of enzymes were examined, although the extracts were prepared from plate-grown cells. A number of enzymes of the CAC were identified, including aconitase, isocitrate dehydrogenase, citrate synthase, 2-oxoglutarate dehydrogenase, succinate dehydrogenase, fumarase and a malic enzyme dependent on NADP. However, no specific activities for the majority of the enzymes were reported.

Hebeler \& Morse (1976) carried out a more comprehensive study of the CAC in N. gonorrhoeae. From extracts of cells grown in conditions of glucose depletion, all the CAC enzymes were identified in addition to phosphoenolpyruvate (PEP) carboxylase, while the extracts from glucose-grown cells lacked activity for aconitase, isocitrate dehydrogenase, malate oxidase (membrane-bound malate dehydrogenase) and PEP carboxylase. PEP carboxylase activity was identified in N. meningitidis (Jyssum \& Jyssum, 1961). The presence of this enzyme was further identified in all strains of Neisseria examined (Holten \& Jyssum, 1974). Further investigations by Holten (1976b) of the malate oxidase established that, unlike malate dehydrogenase, the oxidation of malate was pyridine nucleotide (NAD) independent. Non-pathogenic neisseriae express both a soluble NAD-dependent malate dehydrogenase and a FAD-dependent malate oxidase (Jyssum \& Jyssum, 1961).

The complete genome sequence of $N$. meningitidis Serogroup B strain MC58 (Tettelin et al., 2000) suggests that a complete CAC may be present. In this study we provide firm biochemical evidence to support the predictions from the genome sequence. The central metabolic pathways present in N. meningitidis when grown on pyruvate, lactate and glucose have been investigated. NMR studies were carried out to identify how the various carbon sources were metabolized, to identify any anomalies in amino acid biosynthesis and to give information on the CAC.

\section{METHODS}

Media and growth conditions. Neisseria meningitidis serogroup B strain K454, which was isolated from a blood culture during the Stonehouse meningitis outbreak in Gloucester, UK, was used throughout this study (Cartwright et al., 1986). Stock cultures of N. meningitidis strain K454 were stored in liquid nitrogen or freeze-dried and, when required, were routinely plated onto chocolate blood agar plates and grown overnight at $37{ }^{\circ} \mathrm{C}$ in $5 \% \mathrm{CO}_{2}$. Broth cultures were grown in modified minimal medium (Jyssum, 1960). Solution A contained $166 \mathrm{mM} \mathrm{K}_{2} \mathrm{HPO}_{4}, 62 \mathrm{mM} \mathrm{KH}_{2} \mathrm{PO}_{4}$, in a total of $240 \mathrm{ml}$ water. Solution $\mathrm{B}$ contained $1.66 \mathrm{mM} \mathrm{MgSO}_{4}, 116 \mathrm{mM}$ $\mathrm{NH}_{4} \mathrm{Cl}, 56 \mu \mathrm{M} \mathrm{MnSO}_{4}$, in a total of $240 \mathrm{ml}$ water. Solution C contained $350 \mu \mathrm{M} \mathrm{FeSO}, 250 \mu \mathrm{M} \mathrm{CaCl}_{2}, 7 \cdot 5 \mathrm{mM} \mathrm{Na}_{2} \mathrm{~S}_{2} \mathrm{O}_{3}$, $450 \mathrm{mM}$ pyruvate or DL-lactate or glucose, in a total of $20 \mathrm{ml}$ water. Solutions A and B were sterilized by autoclaving [121 ${ }^{\circ} \mathrm{C}, 15 \mathrm{~min}, 15$ p.s.i. $(103.5 \mathrm{kPa})$ ], while solution $\mathrm{C}$ was filter-sterilized. All three were added together in the volumes stated (final volume of $500 \mathrm{ml}$ ). Sodium bicarbonate was also added to a final concentration of $11 \mathrm{mM}$, before overnight incubation at $37^{\circ} \mathrm{C}$ with shaking at 200 r.p.m. Escherichia coli $(\mathrm{DH} 5-\alpha)$ was grown aerobically overnight in brain-heart infusion (BHI) broth (Oxoid), at $37^{\circ} \mathrm{C}$.

Preparation of cell-free extract (CFE). CFEs were routinely prepared from $500 \mathrm{ml}$ cultures grown aerobically overnight at $37^{\circ} \mathrm{C}$, on pyruvate- or glucose-minimal medium. Cells were harvested by centrifugation $(20 \mathrm{~min}, 6000 \mathrm{~g})$, then resuspended in $1.0 \mathrm{ml} 10 \mathrm{mM}$ Tris $/ \mathrm{HCl}, \mathrm{pH} 8.0$. Following sonication (MSE, $3 \times 30 \mathrm{~s}, 10 \mu \mathrm{m}$ amplitude) the debris was removed by centrifugation $\left(10000 \mathrm{~g}, 25 \mathrm{~min}, 4^{\circ} \mathrm{C}\right)$ and the supernatant (CFE) was stored on ice until required. CFEs for E. coli were prepared the same way, except cultures were grown overnight in BHI broth.

NMR spectroscopy. ${ }^{13} \mathrm{C}$ - and ${ }^{1} \mathrm{H}-\mathrm{NMR}$ spectra were obtained on a Bruker AMX500 spectrometer operating at 125 $\mathrm{MHz}$ and $500 \mathrm{MHz}$ for the ${ }^{13} \mathrm{C}$ and ${ }^{1} \mathrm{H}$ nucleus respectively. For ${ }^{13} \mathrm{C}-\mathrm{NMR}$, pulses of $75^{\circ}(10 \mu \mathrm{s})$ were used, with a spectral width of $33.3 \mathrm{kHz}$ and $16 \mathrm{k}$ complex points, giving an acquisition time of 0.49 s. A 4 s relaxation delay was used and the decoupler was gated on during acquisition only. Preliminary experiments and calculations indicated that these conditions permitted reasonably accurate quantitative comparisons of peak intensity, by ensuring a long enough time for relaxation of carbons with different $T_{1}$ values and by not generating nuclear Overhauser effects. Spectra were Fourier transformed and integrated using FELIX 97.0 (Molecular Simulations). Samples were dissolved in $\mathrm{D}_{2} \mathrm{O}$ and run in $5 \mathrm{~mm}$ tubes at $35^{\circ} \mathrm{C}$. Between 1000 and 3000 scans were accumulated. ${ }^{1} \mathrm{H}-\mathrm{NMR}$ spectra were acquired into $8 \mathrm{k}$ complex points over a spectral width of $12 \cdot 5 \mathrm{kHz}$ and the solvent $\left(\mathrm{H}_{2} \mathrm{O}\right)$ signal was reduced by presaturation for $2 \mathrm{~s}$. This is several times the $T_{1}$ for the signal of interest and thus permits reliable integration of signal intensity. Samples were again run in $5 \mathrm{~mm}$ tubes at $35^{\circ} \mathrm{C}$. Signals in the spectra were assigned by comparison with chemical shifts stated in the literature 
(Rosenthal \& Fendler, 1976; Sprott et al., 1993; Pickett et al., 1994). For ${ }^{1} \mathrm{H}-\mathrm{NMR}$ the concentration of a substrate and end product was established with reference to a standard (trimethylsilylpropionate, TSP) of known concentration, with the number of protons involved taken into account. For example, a peak for TSP and pyruvate of the same area would have concentrations in the ratio of $1: 3$, as the TSP peak results from nine identical protons while the pyruvate enrichment results from just three identical protons.

Preparation of samples for ${ }^{1} \mathbf{H}-\mathbf{N M R}$. Over a $14-16 \mathrm{~h}$ timecourse of growth in minimal medium [with specified carbon source(s)], samples $(1.5 \mathrm{ml})$ were pelleted at intervals by centrifugation $(10000 \mathrm{~g}, 25 \mathrm{~min})$. The supernatant $(1 \mathrm{ml})$ was removed for analysis by ${ }^{1} \mathrm{H}-\mathrm{NMR}$. Growth yields were estimated after determination of the biomass protein concentration using the Lowry method, assuming that cell protein is $50 \%$ of the cell dry weight.

Fractionation of cells for ${ }^{13} \mathrm{C}$-NMR. Cells were harvested $(20 \mathrm{~min}, 6000 \mathrm{~g})$ after overnight growth on 2- or 3$\left[{ }^{13} \mathrm{C}\right]$ pyruvate-minimal medium (18 $\mathrm{mM}$ pyruvate). They were then washed in $10 \mathrm{mM}$ Tris $/ \mathrm{HCl}, \mathrm{pH} 8 \cdot 0$, and resuspended in $1 \mathrm{ml} 20 \mathrm{mM}$ Tris/ $\mathrm{HCl}$ buffer, $\mathrm{pH} 8 \cdot 0$, containing $10 \mathrm{mM}$ magnesium acetate, $30 \mathrm{mM}$ ammonium chloride and $6 \mathrm{mM}$ mercaptoethanol. The cells were then sonicated (MSE, $3 \times 30 \mathrm{~s}, 10 \mu \mathrm{m}$ amplitude) and left on ice for $15 \mathrm{~min}$ after the addition of $0.5 \mathrm{mg}$ DNase. Samples were then centrifuged at $10000 \mathrm{~g}$ for $30 \mathrm{~min}$ and the supernatant was removed. The proteins were then precipitated with ethanol $(60 \%, v / v)$ at $4{ }^{\circ} \mathrm{C}$ and collected by centrifugation $(10000 \mathrm{~g}, 15 \mathrm{~min})$. The protein mixture was hydrolysed for $24 \mathrm{~h}$ in $6 \mathrm{M} \mathrm{HCl}$, under vacuum at $110{ }^{\circ} \mathrm{C}$, and then analysed by ${ }^{13} \mathrm{C}-\mathrm{NMR}$ spectroscopy.

Enzyme assays. CFEs were prepared as described above. All assays were performed spectrophotometrically and carried out aerobically, at room temperature in $1 \mathrm{ml}$ cuvettes. Changes in absorbance were followed on a Shimadzu UV-1601 dualbeam recording spectrophotometer. All enzyme assays were carried out according to Pickett et al. (1994), with the exception of that for pyruvate kinase (Willison, 1988). E. coli CFEs were used as the positive enzyme assay control. Protein concentration was determined using the Lowry FolinCiocalteau reagent.

\section{RESULTS}

\section{Labelling of key amino acids after growth on 2- and 3- $\left[{ }^{13} \mathrm{C}\right]$ pyruvate}

To investigate carbon metabolism in N. meningitidis, cells were grown on $\left[{ }^{13} \mathrm{C}\right]$ pyruvate and the distribution of labels in protein-derived amino acids was determined by ${ }^{13} \mathrm{C}-\mathrm{NMR}$. Several aspects of the CAC were investigated, including the overall direction of the reactions and whether the cycle was complete. The key amino acids examined were alanine, glycine, glutamate and aspartate, which are derived from pyruvate, 3phosphoglycerate, 2-oxoglutarate and oxaloacetate. Their labelling patterns also provided primary information concerning the direction of the CAC. The presence of predicted secondary labels on amino acids, which should be enriched to a lower level than primary labels, indicates a complete CAC being in operation as recycling of oxaloacetate or citrate will occur.

The predicted enrichments of key amino acids after growth on $2-\left[{ }^{13} \mathrm{C}\right]$ pyruvate with an oxidative CAC in operation are: C-1 and C-4 for aspartate; C-1 and C-5 for glutamate and $\mathrm{C}-2$ for both alanine and glycine. The predicted enrichments for growth on $3-\left[{ }^{13} \mathrm{C}\right]$ pyruvate are: C-2 and C-3 for aspartate; C-2, C-3 and C-4 for glutamate; C-3 for alanine and no labelling for glycine (Rosenthal \& Fendler, 1976; Sprott et al., 1993; Pickett et al., 1994).

Figure 1 shows a representative ${ }^{13} \mathrm{C}-\mathrm{NMR}$ spectrum of hydrolysed proteins after growth of cells on $2-\left[{ }^{13} \mathrm{C}\right]-$ pyruvate or $3-\left[{ }^{13} \mathrm{C}\right]$ pyruvate. Initial inspection indicated an abundance of labelled carboxyl groups in the 2$\left[{ }^{13} \mathrm{C}\right]$ pyruvate spectrum, while there were significantly fewer carboxyl enrichments for cells grown on 3$\left[{ }^{13} \mathrm{C}\right]$ pyruvate. For the non-carboxyl labelling, there were substantial enrichments in the $3-\left[{ }^{13} \mathrm{C}\right]$ pyruvate spectrum, while the labelling, in general, for these carbon atoms in the $2-\left[{ }^{13} \mathrm{C}\right]$ pyruvate spectrum was either greatly reduced or not present. The assigned chemical shifts and the relative enrichments of individual carbon atoms of amino acids after growth on 2- and 3$\left[{ }^{13} \mathrm{C}\right]$ pyruvate are shown in Tables 1 and 2 respectively. Individual peaks within the spectra were assigned according to previous data (Rosenthal \& Fendler, 1976; Sprott et al., 1993; Pickett et al., 1994).

Alanine and glycine enrichments after growth on 2$\left[{ }^{13} \mathrm{C}\right]$ pyruvate clearly showed that the two amino acids were labelled at C-2. After growth on $3-\left[{ }^{13} \mathrm{C}\right]$ pyruvate, C-3 alanine labelling was clearly present. Additionally, an unexpected C-2 label was present for glycine, although the enrichment was minimal. Aspartate was labelled on the carboxyl carbons (C-1 and C-4) after growth on $2-\left[{ }^{13} \mathrm{C}\right]$ pyruvate, with the $\mathrm{C}-1, \mathrm{C}-2$ and $\mathrm{C}-3$ carbons labelled after growth on $3-\left[{ }^{13} \mathrm{C}\right]$ pyruvate. Glutamate enrichment was observed at the C-1 and C-3 positions after growth on $2-\left[{ }^{13} \mathrm{C}\right]$ pyruvate, while the central carbons (C-2, C-3 and C-4) and C- 1 were labelled after growth on $3-\left[{ }^{13} \mathrm{C}\right]$ pyruvate. Taken together, all of these observations implied that an oxidative CAC was in operation.

A more detailed examination of the derivatives of the key amino acids after growth on $2-\left[{ }^{13} \mathrm{C}\right]$ pyruvate showed labelling consistent with the expected biosynthetic pathways. For example, threonine, isoleucine and methionine exhibited the predicted enrichments for biosynthesis from aspartate. Lysine also had predicted enrichments, although there was some additional labelling of C-3. Valine and leucine both had labelling patterns consistent with their derivation from pyruvate. Additionally, serine and cysteine, which are derived from 3-phosphoglycerate, had the predicted C-2 label, but both had an additional C-3 label.

A more comprehensive analysis of amino acid enrichments after growth on $3-\left[{ }^{13} \mathrm{C}\right]$ pyruvate (Table 2 ) showed not only extensive predicted labelling, but also the presence of numerous secondary labels at lower enrichments. It was not possible to unequivocally establish the individual origins of the majority of the carboxyl labels in this case. Threonine and methionine, which are both derived from aspartate, exhibited similar labelling to 


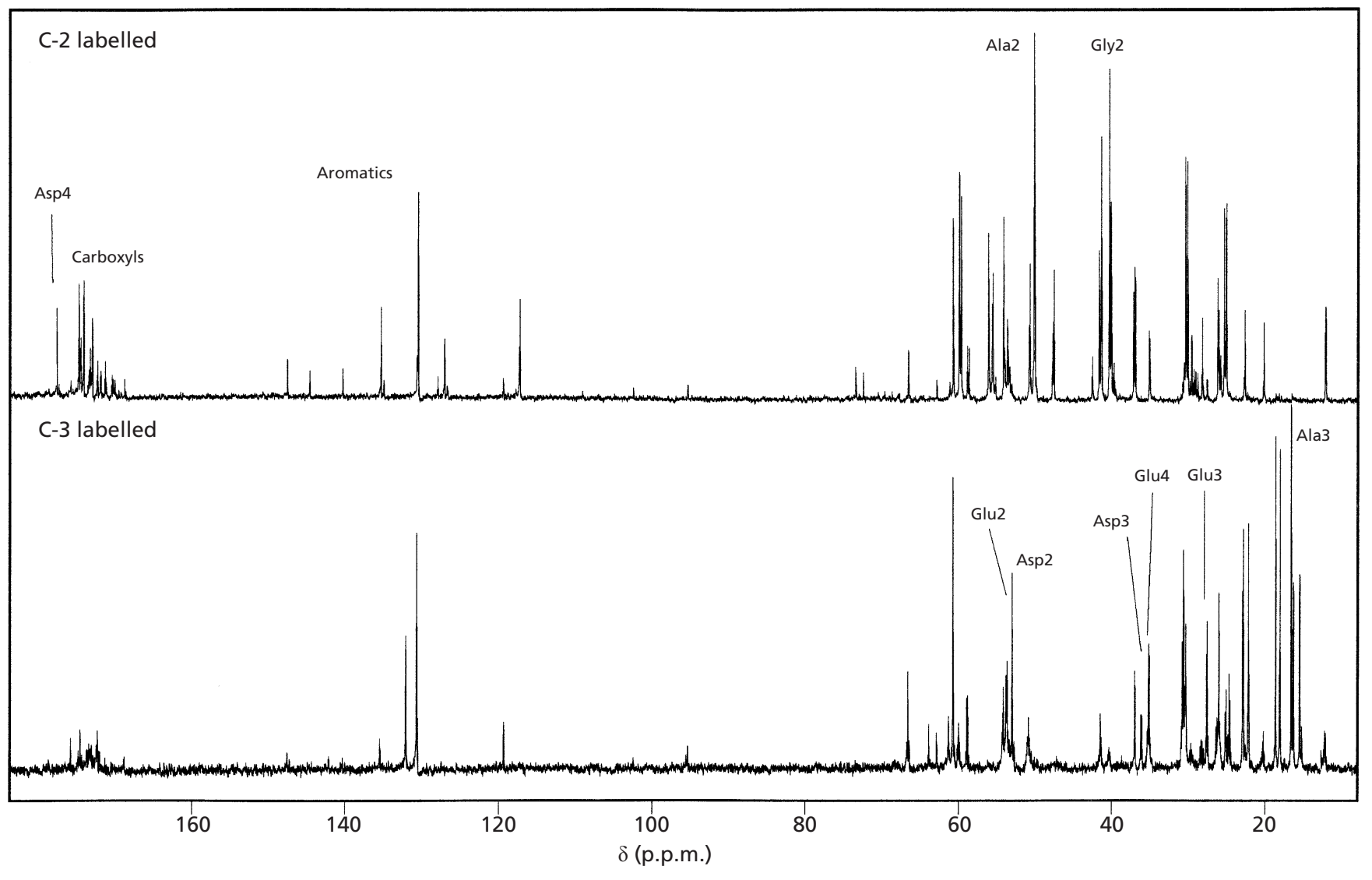

Fig. 1. Representative ${ }^{13} \mathrm{C}-\mathrm{NMR}$ spectrum of hydrolysed cell protein from $N$. meningitidis cells grown on $2-\left[{ }^{13} \mathrm{C}\right]$ pyruvate (upper panel) or $3-\left[{ }^{13} \mathrm{C}\right]$ pyruvate (lower panel). Cells were grown aerobically overnight at $37{ }^{\circ} \mathrm{C}$ in modified minimal medium (Jyssum, 1960), with the inclusion of $\left[{ }^{13} \mathrm{C}\right]$ pyruvate. Proteins in the cell lysate were hydrolysed prior to NMR analysis as described in Methods. Enrichments were assigned by comparison with chemical shifts stated in the literature (Rosenthal \& Fendler, 1976; Sprott et al., 1993; Pickett et al., 1994). The major enrichments assigned to the four key amino acids (alanine, glycine, aspartate and glutamate) are indicated. The predicted enrichments of these amino acids are given in the text, while comprehensive assignments of other amino acids are given in Tables 1 and 2 for 2 $\left[{ }^{13} \mathrm{C}\right]$ pyruvate and $3-\left[{ }^{13} \mathrm{C}\right]$ pyruvate respectively.

their precursor. Additionally, isoleucine and lysine had three predicted enrichments. Pyruvate derivatives, valine and leucine, had several unexpected labels. Valine had an additional C-2 label, while leucine had C-1 and C-3, although these were enriched to lower levels than the expected labels. Serine and cysteine, synthesized from 3phosphoglycerate, had a single predicted enrichment in C-3. The predicted secondary labels of aspartate, threonine and methionine were identified at the C-1 position, with the relative enrichment being very low compared to the predicted primary labels. Finally, arginine and proline had the expected labels, although arginine had an additional C-1 label enriched to a lower level than the C-2 and C-4. As mentioned previously, the presence of these secondary labels indicates a complete CAC in operation, with recycling of oxaloacetate.

\section{Analysis of enzyme activities in $\boldsymbol{N}$. meningitidis}

The above results suggested that the $N$. meningitidis CAC operated in an oxidative direction when cells were grown on either 2- or $3-\left[{ }^{13} \mathrm{C}\right]$ pyruvate. The data also implied that all the CAC enzymes were present. This was confirmed by performing individual enzyme assays using cell-free extracts of both pyruvate- and glucosegrown cells. The activities of the enzymes of the CAC are shown in Table 3.

Activities of all of the enzymes of a complete CAC were detected in extracts of cells grown on either pyruvate or glucose. However, the specific activities for most of the CAC enzymes were significantly higher (three- to fivefold) in glucose-grown cells. This may be partially due to an increase in the organism's growth rate (doubling times of 70 and $53 \mathrm{~min}$ on pyruvate and glucose, respectively). The largest difference observed was the activity of pyruvate dehydrogenase, which was more than 10-fold higher in glucose-grown cells.

The oxidation of succinate to fumarate by succinate dehydrogenase was detected via a dye-linked assay. This enzyme is membrane bound and transfers electrons from succinate to enzyme-bound FAD. Electrons are subsequently channelled to the respiratory chain. Activity of succinate dehydrogenase was also identified in 
Table 1. Enrichments of individual amino acid carbon atoms after growth of N. meningitidis on $2-\left[{ }^{13} \mathrm{C}\right]$ pyruvate

The chemical shifts of particular carbon atoms correspond to the resonance of the atom in relation to a TSP standard at 0 p.p.m. The relative levels of enrichment within a particular amino acid (values in parentheses) were measured by comparing the areas of individual NMR peaks, which is effectively a comparison of concentrations of individual labels, with the smallest peak given a value of 1 .

\begin{tabular}{|c|c|c|c|c|c|c|}
\hline \multirow[t]{2}{*}{ Amino acid } & \multicolumn{6}{|c|}{ Chemical shift in p.p.m. (relative enrichment) } \\
\hline & C-1 & C-2 & $\mathrm{C}-3$ & C-4 & $\mathrm{C}-5$ & C-6 \\
\hline Alanine & & $49 \cdot 1$ & & & & \\
\hline Serine & & $54 \cdot 1(1 \cdot 2)$ & $60 \cdot 6(1)$ & & & \\
\hline Glycine & & $40 \cdot 3$ & & & & \\
\hline Aspartate & $177 \cdot 6(1)$ & & & $174 \cdot 6(1 \cdot 4)$ & & \\
\hline Glutamate & $174 \cdot 5(1)$ & & $28 \cdot 5(1 \cdot 0)$ & & & \\
\hline Threonine & $173 \cdot 5(1)$ & & & $20(1 \cdot 5)$ & & \\
\hline Arginine & $174 \cdot 1(1)$ & & & $40 \cdot 9(2 \cdot 5)$ & & \\
\hline Proline & & & & & $47 \cdot 0$ & \\
\hline Leucine & $172(1)$ & & $39 \cdot 8(4 \cdot 0)$ & $25 \cdot 1(4 \cdot 3)$ & & \\
\hline Valine & & $59 \cdot 8(1 \cdot 1)$ & $30 \cdot 2(1)$ & & & \\
\hline Isoleucine & $172 \cdot 3(1)$ & & & $25 \cdot 5(3 \cdot 3)$ & & \\
\hline Methionine & $175 \cdot 6(1)$ & & $30 \cdot 6(12 \cdot 5)$ & $12 \cdot 5(4 \cdot 5)$ & & \\
\hline Cysteine & & $55 \cdot 5(1)$ & $26 \cdot 5(1)$ & & & \\
\hline Lysine & & $55 \cdot 6(1 \cdot 4)$ & $29 \cdot 5(1)$ & $22 \cdot 5(1 \cdot 1)$ & & \\
\hline
\end{tabular}

Table 2. Enrichments of individual amino acid carbon atoms after growth of $N$. meningitidis on $3-\left[{ }^{13} \mathrm{C}\right]$ pyruvate

The enrichments were calculated as described in the legend to Table 1.

\begin{tabular}{|c|c|c|c|c|c|c|}
\hline \multirow[t]{2}{*}{ Amino acid } & \multicolumn{6}{|c|}{ Chemical shift in p.p.m. (relative enrichment) } \\
\hline & C-1 & C-2 & C-3 & C-4 & C-5 & C-6 \\
\hline Alanine & & & $16 \cdot 5$ & & & \\
\hline Serine & & & $60 \cdot 7$ & & & \\
\hline Glycine & & $41 \cdot 2$ & & & & \\
\hline Aspartate & $174 \cdot 8(1)$ & $52.9(8.5)$ & $36 \cdot 25(3 \cdot 5)$ & & & \\
\hline Glutamate & $174 \cdot 3(1)$ & $53 \cdot 6(3)$ & $27 \cdot 4(4 \cdot 0)$ & $37(3 \cdot 3)$ & & \\
\hline Threonine & $173 \cdot 1(1)$ & $58 \cdot 8(3)$ & $66 \cdot 6(2 \cdot 5)$ & & & \\
\hline Arginine & $174 \cdot 6(1)$ & $53 \cdot 5(3)$ & $28 \cdot 3(1)$ & $24 \cdot 5(2)$ & & \\
\hline Proline & & $61 \cdot 2(2)$ & $28 \cdot 5(1)$ & $22.9(6 \cdot 8)$ & & \\
\hline Leucine & $172 \cdot 2(1)$ & $50 \cdot 9(1)$ & $41 \cdot 3(1 \cdot 2)$ & $25(1 \cdot 5)$ & $22(5)$ & \\
\hline Valine & & $60 \cdot 5(1)$ & & $18(7)$ & & \\
\hline Isoleucine & & $59 \cdot 8(1)$ & $36(2 \cdot 3)$ & & $11 \cdot 6(2 \cdot 3)$ & \\
\hline Methionine & $175 \cdot 6(1)$ & $54 \cdot 2(2)$ & $30 \cdot 4(4 \cdot 2)$ & & & \\
\hline Cysteine & & & $25 \cdot 9$ & & & \\
\hline Lysine & & & $30 \cdot 1(4 \cdot 3)$ & & $26 \cdot 1(2)$ & $40 \cdot 3(1)$ \\
\hline
\end{tabular}

membrane fractions (data not shown). Two enzymes are capable of the oxidation of malate to oxaloacetate, namely malate dehydrogenase and malate:acceptor oxidoreductase or malate 'oxidase'. Cell-free extracts of N. meningitidis did not exhibit any detectable activity of the typical NAD-dependent malate dehydrogenase. However, a dye-linked malate 'oxidase' was detected, in CFEs and membrane fractions (data not shown). This enzyme is thought to be FAD dependent (Holten, 1976b) and is probably the malate:quinone oxidoreductase (NMB2069) predicted in the genome sequence (Tettelin et al., 2000).

Anaplerotic $\mathrm{CO}_{2}$-fixation enzymes, including PEP carboxylase, PEP carboxykinase and pyruvate carboxylase, were assayed. Of these, only PEP carboxylase was 
Table 3. Enzyme activities in cell-free extracts of $N$. meningitidis $\mathrm{K} 454$ after growth on pyruvate or glucose minimal medium

The values for enzyme activities are mean values taken from three or more separate experiments, with standard deviations shown in parentheses. Cells were grown to early stationary phase and CFEs were prepared. ND, Not determined.

\begin{tabular}{|c|c|c|}
\hline \multirow[t]{2}{*}{ Enzyme } & \multicolumn{2}{|c|}{ Specific activity $\left[\mathrm{nmol} \mathrm{min}^{-1}(\mathrm{mg} \text { protein })^{-1}\right]$} \\
\hline & Pyruvate-grown & Glucose-grown \\
\hline Pyruvate dehydrogenase & $58( \pm 13)$ & $668( \pm 304)$ \\
\hline Citrate synthase & $181( \pm 54)$ & $218( \pm 85)$ \\
\hline Aconitase & $77( \pm 16)$ & $201( \pm 157)$ \\
\hline Isocitrate dehydrogenase & $208( \pm 49)$ & $479( \pm 127)$ \\
\hline 2-Oxoglutarate dehydrogenase & $41( \pm 14)$ & $146( \pm 15)$ \\
\hline Succinate thiokinase & $23( \pm 7)$ & $85( \pm 29)$ \\
\hline Succinate dehydrogenase & $18( \pm 5)$ & $94( \pm 67)$ \\
\hline Fumarase & $28( \pm 5)$ & $99( \pm 42)$ \\
\hline Malate 'oxidase' & $4 \cdot 7( \pm 1 \cdot 5)$ & $35( \pm 15)$ \\
\hline PEP carboxylase & $31( \pm 8)$ & $130( \pm 32)$ \\
\hline PEP carboxykinase & 0 & 0 \\
\hline Pyruvate kinase & $23( \pm 1 \cdot 1)$ & $22( \pm 16)$ \\
\hline PEP synthetase & 0 & $14( \pm 4.4)$ \\
\hline Acetate thiokinase & 0 & $\mathrm{ND}$ \\
\hline Malate dehydrogenase & 0 & ND \\
\hline Malate synthase & 0 & ND \\
\hline Isocitrate lyase & 0 & ND \\
\hline
\end{tabular}

Table 4. Analysis of phosphotransacetylase (PTA) and acetate kinase (ACK) activity in N. meningitidis after growth on single and dual carbon sources

PTA and ACK activity were assayed as described in Methods. Activities are the means of three separate experiments, with standard deviations shown in parentheses.

\begin{tabular}{|lcc|}
\hline Carbon source $(\mathbf{s})$ & \multicolumn{2}{c|}{ Activity $\left[\mathbf{n m o l ~} \mathbf{~ m i n}^{-1}(\mathbf{m g} \text { protein })^{-1}\right]$} \\
\cline { 2 - 3 } & PTA & ACK activity \\
\hline Pyruvate & $7436( \pm 1194)$ & $46( \pm 12)$ \\
Lactate & $9366( \pm 985)$ & $88.1( \pm 10)$ \\
Glucose & $11383( \pm 1262)$ & $105( \pm 17)$ \\
Pyruvate/lactate & $13828( \pm 1503)$ & $103( \pm 23)$ \\
Pyruvate/glucose & $8705( \pm 1040)$ & $298( \pm 74)$ \\
Lactate/glucose & $9010( \pm 597)$ & $278( \pm 78)$ \\
\hline
\end{tabular}

detectable (Table 3). The ATP-dependent synthesis of PEP from pyruvate can be achieved via two enzymes, PEP synthetase and pyruvate phosphate dikinase (Cooper \& Kornberg, 1974). A low PEP synthetase activity was detected in glucose-grown cells but not in pyruvate-grown cells. Pyruvate kinase was detected at a similar specific activity in both pyruvate- and glucosegrown cells.

Extremely high activity corresponding to phosphotransacetylase (PTA) was detected in CFEs (Table 4).
Acetate kinase (ACK), the subsequent enzyme in the conversion of acetyl-CoA to acetate, also had detectable activity, although considerably lower than that of phosphotransacetylase (Table 4). To confirm the presence of ACK, $P^{1}, P^{5}$-di(adenosine- $\left.5^{\prime}\right)$ pentaphosphate $\left(\mathrm{AP}_{5} \mathrm{~A}\right)$, which inhibits acetate thiokinase but not acetate kinase activity (Lienhard \& Secemski, 1973), was used. It was demonstrated that the reaction was dependent on acetate but not CoA and was not inhibited by $\mathrm{AP}_{5} \mathrm{~A}$ (data not shown).

Finally the glyoxalate bypass enzymes, isocitrate lyase and malate synthase, were not detected in CFEs.

\section{${ }^{1} \mathrm{H}-\mathrm{NMR}$ analysis of substrate utilization and acetate release during growth on various carbon sources}

To study patterns of carbon utilization and end product excretion, ${ }^{1} \mathrm{H}-\mathrm{NMR}$ analysis was carried out. Preliminary experiments involving growth of $N$. meningitidis on pyruvate showed that by the end of the growth period a significant amount of acetate was excreted into the medium. Acetate excretion occurred even though the bacteria were grown aerobically in minimal medium where most of the pyruvate present would be expected to enter the CAC and be oxidized to $\mathrm{CO}_{2}$.

More detailed investigations of the utilization of the carbon source and the release of the end product were carried out in order to establish the patterns of utilization and excretion, and the relationship between 
Table 5. Acetate conversion and growth yields

Comparison of percentage acetate conversion and growth yields for three different carbon sources, at stationary phase $(14 \mathrm{~h})$. These conversions were calculated assuming that one molecule of glucose would lead to the production of two molecules of pyruvate and a maximum of two molecules of acetate. In addition, one molecule of lactate or pyruvate would lead to the production of one molecule of acetate. The figures are from a representative experiment that was repeated several times. Pyruvate and acetate concentrations were determined by ${ }^{1} \mathrm{H}-\mathrm{NMR}$ as described in Methods.

\begin{tabular}{|c|c|c|c|c|c|c|}
\hline \multirow[t]{2}{*}{ C source } & \multicolumn{2}{|c|}{$\begin{array}{c}\text { C source } \\
\text { concn }(\mathrm{mM})\end{array}$} & \multicolumn{2}{|c|}{$\begin{array}{l}\text { Acetate concn } \\
\qquad(\mathrm{mM})\end{array}$} & \multirow{2}{*}{$\begin{array}{c}\text { Percentage of C } \\
\text { source converted to } \\
\text { acetate }\end{array}$} & \multirow[t]{2}{*}{$\begin{array}{l}\text { Growth yield [g } \\
\left.(\text { mol C source })^{-1}\right]\end{array}$} \\
\hline & Initial & Final & Initial & Final & & \\
\hline Pyruvate & 5 & $0 \cdot 04$ & 0 & $2 \cdot 1$ & 42 & 40 \\
\hline Lactate & $12 \cdot 4$ & 0 & 0 & $1 \cdot 65$ & 13 & 19 \\
\hline Glucose & $6 \cdot 7$ & 0 & 0 & $4 \cdot 6$ & 34 & 105 \\
\hline
\end{tabular}

carbon source and acetate production (Table 5). Growth on pyruvate led to $42 \%$ of the initial pyruvate being converted to acetate and excreted by the end of the experiment. In contrast, when lactate was provided as the sole carbon source, only $13 \%$ of the substrate was converted to acetate. The growth yield from pyruvate was $40 \mathrm{~g} \mathrm{~mol}^{-1}$, while for DL-lactate the growth yield was only $19 \mathrm{~g} \mathrm{~mol}^{-1}$. When glucose was supplied as a sole carbon source $34 \%$ of the glucose was converted to acetate (growth yield of $105 \mathrm{~g} \mathrm{~mol}^{-1}$ ).

\section{Effect of carbon source on PTA and ACK activity}

From the analysis of enzyme activities it was found that PTA was present at an extremely high specific activity compared to all other enzymes assayed. With the identification of ACK it is likely that the excretion of acetate occurs via the PTA/ACK pathway. Table 4 gives specific activities for PTA and ACK after growth on various carbon sources. Growth on pyruvate resulted in the lowest PTA and ACK activities. Growth on DLlactate resulted in a 1.25-fold increase in PTA activity and a two-fold increase in ACK activity, when compared to that observed for growth on pyruvate. For growth on a single carbon source the highest activities were observed for glucose, where there was a $1 \cdot 5$-fold increase in PTA activity and a 2-3-fold increase in ACK activity compared to growth on pyruvate. The highest PTA activity was observed after growth on a combination of pyruvate/DL-lactate, this led to $1 \cdot 85$-fold and $2 \cdot 2$-fold increases in PTA and ACK activities, respectively. Growth on pyruvate/glucose or DL-lactate/glucose, both resulted in approximately $1 \cdot 2$-fold increases in PTA activity, compared to growth on pyruvate alone. However, the highest ACK activities were observed under these growth conditions; 6.6- and 6.1-fold increases in activities respectively. Thus, when $N$. meningitidis was grown on single carbon sources, an increase in PTA activity was accompanied by a concomitant increase in ACK activity. However, growth on dual carbon sources resulted in an inverse relationship, with the highest ACK activities being observed with the lowest PTA activity.
For both single and dual carbon sources the changes in activity were not proportional.

\section{DISCUSSION}

The recent publication of the N. meningitidis serogroup $\mathrm{B}$ genome sequence has provided evidence for a complete CAC, based on the presence of homologues of all the usual CAC enzymes, except NAD-linked malate dehydrogenase (Tettelin et al., 2000). However, the CAC has previously only been partially characterized at the biochemical level in pre-genome era investigations (Holten, 1976a; Jyssum, 1960). In this study we sought evidence from both NMR labelling experiments and conventional enzyme assays for the presence and nature of the CAC in N. meningitidis.

The direct comparison of labelling of key amino acids derived from cells grown on $2-\left[{ }^{13} \mathrm{C}\right]$ pyruvate and 3 $\left[{ }^{13} \mathrm{C}\right]$ pyruvate (Fig. 1) allowed the overall nature of the CAC in N. meningitidis to be assessed. The abundance of carboxyl labels in amino acids after growth on 2$\left[{ }^{13} \mathrm{C}\right]$ pyruvate was an initial indicator that an oxidative CAC was operating. Additional evidence included the labelling of the central carbons of glutamate and aspartate (C-2, C-3 and C-4, and C-2 and C-3, respectively) in the spectra from cells grown on 3$\left[{ }^{13} \mathrm{C}\right]$ pyruvate. Also, the presence of the $\mathrm{C}-2$ alanine and glycine labels, but the absence of the $\mathrm{C}-3$ alanine label $\left(2-\left[{ }^{13} \mathrm{C}\right]\right.$ pyruvate growth), was indicative. The identification of numerous secondary labels in a variety of amino acids, from growth on both 2- and 3$\left[{ }^{13} \mathrm{C}\right]$ pyruvate, is also indicative that the CAC is complete.

A number of peaks in the spectra could not be assigned unambiguously. This is particularly evident for the carboxyl groups, where there are a large number of enrichments with similar chemical shifts. Hence there are several predicted carboxyl labels in several amino acids that could not be identified, for example the expected threonine C-1 $\left(3-{ }^{13} \mathrm{C}\right)$, glutamate C-5 $\left(2-{ }^{13} \mathrm{C}\right)$ and lysine $\mathrm{C}-1\left(3-{ }^{13} \mathrm{C}\right)$ were not apparent. Secondly there 
was a certain extent of scrambling, which leads to unexpected enrichments, such as the C3 from methionine, leucine, glutamate, lysine, serine and cysteine (all from growth on $2-\left[{ }^{13} \mathrm{C}\right]$ pyruvate). Scrambling arises due to the bacteria recycling and degrading amino acids and CAC intermediates.

The presence of a fully functional CAC enzyme complement was established in this study, supporting the data obtained in the ${ }^{13} \mathrm{C}$-NMR. It should be noted that the meningococcal genome sequence contains two genes for both aconitase and fumarase (Tettelin et al., 2000); therefore the activity we have observed may not be due to a single enzyme in these cases. PEP synthetase and pyruvate kinase (PK) were identified in the meningococcal genome sequence (Tettelin et al., 2000) and were detected via conventional enzyme assays in this study. However, PEP synthetase could not be detected in pyruvate-grown cells. The coupled assay used may not be suitable for the detection of low activities of this enzyme. PK is the final step in glycolysis, converting PEP to pyruvate, but the specific activities of this enzyme were similar in both pyruvate-grown cells and glucosegrown cells.

An extremely high PTA activity was demonstrated in this study, although ACK had a much lower activity. In most bacteria, these enzymes form part of a fermentative pathway, with acetate as the end product. However, PTA appears to be a key enzyme in meningococcal metabolism during growth on glucose, pyruvate, or DLlactate. It utilizes the pivotal metabolic intermediate acetyl-CoA to produce acetyl phosphate. The main effect of this is to reduce the level of energy conservation from an individual carbon source because of the conversion of carbon to acetate production and not through oxidation via the CAC.

From ${ }^{1} \mathrm{H}-\mathrm{NMR}$ data, it was apparent that pyruvate, glucose and lactate were metabolized by both the CAC and the PTA-ACK pathways, the latter resulting in the excretion of acetate. This is in agreement with previous investigations in the closely related bacterium $N$. gonorrhoeae (Hebeler \& Morse, 1976). When meningococci were grown on either pyruvate, glucose, or lactate, it was found that they exhibited very different levels of acetate production and growth yield. As would be expected, growth on glucose gave a higher growth yield than for pyruvate or lactate. Apart from extra ATP produced by substrate-level phosphorylation during glucose catabolism to pyruvate, both lactate and pyruvate need to feed into the gluconeogenesis pathway as well as the CAC in order to allow synthesis of carbohydrates, resulting in lower growth yields compared to growth on a sugar. Growth on DL-lactate gave both the lowest growth yield and the least acetate excretion. This contradicts the work of Erwin \& Gotschlich (1993), who showed that N. meningitidis was able to grow on lactate at least as well as on glucose. Growth on lactate requires the presence of LDH; Erwin \& Gotschlich (1996) demonstrated the presence of at least two L-lactate-specific LDHs and one D-lactate- specific LDH in N. meningitidis. This has recently been confirmed by the genome sequence (Tettelin et al., 2000). The bioenergetics of growth on lactate by $N$. meningitidis is clearly less favourable than growth on pyruvate. This is possibly due to the utilization of NAD, but $N$. meningitidis possesses a cytoplasmic LDH, the activity of which is greater with NADH, which favours the formation of lactate from pyruvate (Holten \& Jyssum, 1974). Therefore, the oxidation of lactate to pyruvate is thought to occur via two membraneassociated LDHs that are specific for either L- or Dlactate and feed electrons directly from lactate into the electron-transport chain at the level of the quinone pool (Erwin \& Gotschlich, 1993, 1996). Thus, growth on lactate could result in over-reduction of the quinone pool and lead to redox-balancing problems for the bacteria, which may lower the growth yield compared to growth on pyruvate.

Large amounts of acetate were shown to be excreted into the medium during growth of $N$. meningitidis on pyruvate. This has been found in other bacteria during growth where the carbon source is in excess and may represent an 'overflow' metabolism due to the inability to control carbon-substrate uptake (Elmansi \& Holms, 1989). The consumption of carbon is in excess of that needed to support the growth rate and the excess carbon is excreted as acetate.

The analysis of PTA and ACK activities, on a range of carbon sources, was carried out in order to establish whether there was a relationship between the amount of acetate excreted into the medium and the relative PTA and ACK specific activities. When meningococci were grown on a single carbon source there appeared to be a pattern of related activity between PTA and ACK, suggesting co-regulation. During growth on a single carbon source the highest PTA activity also corresponded to the highest ACK activity. However, growth on dual carbon sources resulted in an inverse relationship, where the lowest PTA activity corresponded to the highest ACK activity. In other prokaryotes the genes for both of these enzymes are usually co-transcribed in a single operon (Boynton et al., 1996; Latimer \& Ferry, 1993; Matsuyama et al., 1994; Summers et al., 1999). However, the genome sequence of N. meningitidis has, unusually, revealed the presence of two separate ACK genes which are unlinked to the gene encoding PTA (Tettelin et al., 2000). This arrangement may explain the variation in the PTA and ACK activities observed in this study.

Interestingly, the product of the PTA reaction, acetyl phosphate, has been implicated as a global regulator (Nyström, 1994; Wanner, 1992; McCleary et al., 1993; McCleary \& Stock, 1994; Wanner \& WilmesReisenberg, 1992). This is thought to occur via the replacement of the phosphate donor in two-component regulatory systems, where acetyl phosphate acts directly on the response regulator (Wanner, 1992). However, the physiological significance of this remains controversial (McCleary, 1996). Growth on different carbon sources 
located at diverse sites within the human host will affect both PTA and ACK activities and alter the intracellular pool of acetyl phosphate. This could possibly be used as a global signal by the bacterium during pathogenesis. Indeed, mutants of PTA and pyruvate oxidase, another enzyme that converts pyruvate to acetyl phosphate, affect the virulence of Vibrio cholerae and Streptococcus pneumoniae, respectively (Chiang \& Mekalanos, 1998; Spellerberg et al., 1996).

\section{ACKNOWLEDGEMENTS}

We are grateful to the University of Sheffield Faculty of Medicine for the research studentship to M.L.

\section{REFERENCES}

Boynton, Z. L., Bennett, G. N. \& Rudolph, F. B. (1996). Cloning, sequencing and expression of genes encoding phosphotransacetylase and acetate kinase from Clostridium acetobutylicum ATCC 824. Appl Environ Micobiol 62, 2758-2766.

Cartwright, K. A. V., Stuart, J. M. \& Noah, N. D. (1986). An outbreak of meningococcal disease in Gloucestershire. Lancet 8506, 558-561.

Chapin, C. W. (1918). Carbon dioxide in the primary cultivation of the gonococcus. J Infect Dis 19, 342-343.

Chiang, S. L. \& Mekalanos, J. J. (1998). Use of signature-tagged transposon mutagenesis to identify Vibrio cholerae genes critical for colonization. Mol Microbiol 27, 797-805.

Cooper, R. M. \& Kornberg, H. L. (1974). Phosphotransacetylase synthetase and pyruvate phosphate dikinase. In The Enzymes, vol. 10, pp. 6331-649. Edited by P. D. Boyer. New York: Academic Press.

Elmansi, E. M. T. \& Holms, W. H. (1989). Control of carbon flux to acetate excretion during growth of Escherichia coli in batch and continuous cultures. J Gen Microbiol 135, 2875-2883.

Erwin, A. L. \& Gotschlich, E. M. (1993). Oxidation of D-lactate and L-lactate by Neisseria meningitidis: purification and cloning of meningococcal D-lactate dehydrogenase. J Bacteriol 175, 6382-6391.

Erwin, A. L. \& Gotschlich, E. M. (1996). Cloning of a Neisseria meningitidis gene for L-lactate dehydrogenase (L-LDH) : evidence for a second meningococcal L-LDH with different regulation. $J$ Bacteriol 178, 4807-4813.

Hebeler, B. H. \& Morse, S. A. (1976). Physiology and metabolism of pathogenic Neisseria: tricarboxylic acid cycle activity in Neisseria gonorrhoeae. J Bacteriol 128, 192-201.

Holten, E. (1974a). Glucokinase and glucose 6-phosphate dehydrogenase in Neisseria. Acta Pathol Microbiol Scand Sect B 82, 201-206.

Holten, E. (1974b). 6-Phosphogluconate dehydrogenase and enzymes of the Entner-Doudoroff pathway in Neisseria. Acta Pathol Microbiol Scand Sect B 82, 207-213.

Holten, E. (1975). Radiorespirometric studies in the genus Neisseria. 1. The catabolism of glucose. Acta Pathol Microbiol Scand Sect B 83, 353-366.

Holten, E. (1976a). Radiorespirometric studies in the genus Neisseria. 3. The catabolism of pyruvate and acetate. Acta Pathol Microbiol Scand Sect B 84, 9-16.

Holten, E. (1976b). Pyridine nucleotide independent oxidation of L-malate in the genus Neisseria. Acta Pathol Microbiol Scand Sect B 84, 17-21.
Holten, E. \& Jyssum, K. (1974). Activities of some enzymes concerning pyruvate metabolism in Neisseria. Acta Pathol Microbiol Scand Sect B 82, 843-848.

Jyssum, K. (1960). Intermediate reactions of the tricarboxylic acid cycle in meningococci. Acta Pathol Microbiol Scand Sect B 48, 121-132.

Jyssum, K. \& Jyssum, S. (1961). Phosphoenolpyruvic carboxylase activity in extracts from Neisseria meningitidis. Acta Pathol Microbiol Scand Sect B 54, 412-424.

Klein, N. J., Heydermann, R. S. \& Levin, M. (1993). Management of meningococcal infections. Br Med J 50, 42-49.

Latimer, M. T. \& Ferry, J. G. (1993). Cloning, sequence analysis, and hyperexpression of the genes encoding phosphotransacetylase and acetate kinase from Methanosarcina thermophila. J Bacteriol 175, 6822-6829.

Lienhard, G. E. \& Secemski, I. I. (1973). P1,P5-Di(adenosine-5') pentaphosphate, a potent multisubstrate inhibitor of adenylate kinase. J Biol Chem 248, 1121-1123.

Matsuyama, A., Yamamoto-Otake, H., Hewitt, J., MacGillivray, R. T. A. \& Nakano, E. (1994). Nucleotide sequence of the phosphotransacetylase gene of Escherichia coli K12. Biochim Biophys Acta 1219, 559-562.

McCleary, W. R. (1996). The activation of PhoB by acetylphosphate. Mol Microbiol 20, 1155-1163.

McCleary, W. R. \& Stock, J. B. (1994). Acetyl phosphate and the activation of two-component response regulators. J Biol Chem 269, 31567-31572.

McCleary, W. R., Stock, J. B. \& Ninfa, A. J. (1993). Is acetyl phosphate a global signal in Escherichia coli? J Bacteriol 175, 2793-2798.

Morse, J. R. (1979). The biology of the gonococcus. Crit Rev Microbiol 7, 93-189.

Morse, S. A., Cacciapuoti, A. F. \& Lysko, P. (1979). Physiology of Neisseria gonorrhoeae. Adv Microb Physiol 20, 251-320.

Nyström, T. (1994). The glucose-starvation stimulon of Escherichia coli: induced and repressed synthesis of enzymes of central metabolic pathways and role of acetyl phosphate in gene expression and starvation survival. Mol Microbiol 12, 833-843.

Pickett, M. W., Williamson, M. P. \& Kelly, D. J. (1994). An enzyme and ${ }^{13} \mathrm{C}-\mathrm{NMR}$ study of carbon metabolism in heliobacteria. Photosynth Res 41, 75-88.

Rosenthal, S. N. \& Fendler, J. H. (1976). ${ }^{13} \mathrm{C}-\mathrm{NMR}$ spectroscopy in macromolecular systems of biological interest. Adv Phys Org Chem 13, 279-423.

Spellerberg, B., Cundell, D. R., Sandros, J. \& 4 other authors (1996). Pyruvate oxidase, as a determinant of virulence in Streptococcus pneumoniae. Mol Microbiol 19, 803-813.

Sprott, G. D., Ekiel, I. \& Patel, G. P. (1993). Metabolic pathways in Methanococcus jannaschii and other methanogenic bacteria. Appl Environ Microbiol 59, 1092-1098.

Summers, M. L., Dentom, M. C. \& McDermott, T. R. (1999). Genes coding for phosphotransacetylase and acetate kinase in Sinorhizobium meliloti are in an operon that is inducible by phosphate stress and controlled by PhoB. J Bacteriol 181, 2217-2224.

Tettelin, H., Saunders, N. J., Heidelberg, J. \& 39 other authors (2000). Complete genome sequence of Neisseria meningitidis serogroup B strain MC58. Science 287, 1809-1815.

Tonhazy, N. E. \& Pelczar, M. J. (1953). Oxidation of amino acids and compounds associated with the tricarboxylic acid cycle by Neisseria gonorrhoeae. J Bacteriol 65, 368-377.

Wanner, B. L. (1992). Is cross regulation by phosphorylation of 
two-component response regulator proteins important in bacteria? J Bacteriol 174, 2053-2058.

Wanner, B. L. \& Wilmes-Reisenberg, M. R. (1992). Involvement of phosphotransacetylase, acetate kinase, and acetyl phosphate synthesis in control of the phosphate regulon in Escherichia coli. J Bacteriol 174, 2124-2130.
Willison, J. C. (1988). Pyruvate and acetate metabolism in the photosynthetic bacterium Rhodobacter capsulatus. J Gen Microbiol 134, 2429-2439.

Received 11 December 2000; accepted 14 February 2001. 